\title{
Intercomparison of IRS-P4-MSMR derived geophysical products with DMSP-SSM/I and TRMM-TMI finished products
}

\author{
A K Varma, ${ }^{*}$ R M Gairola, A K Mathur, B S Gohil and Vijay K Agarwal \\ Oceanic Sciences Division, \\ Remote Sensing Applications Area, \\ Space Applications Centre (ISRO), \\ Ahmedabad 380 015, India. \\ *e-mail: atul_varma@hotmail.com
}

In this paper, MSMR geophysical products like Integrated Water Vapour (IWV), Ocean Surface Wind Speed (OWS) and Cloud Liquid Water (CLW) in different grids of 50, 75 and $150 \mathrm{kms}$ are compared with similar products available from other satellites like DMSP-SSM/I and TRMMTMI. MSMR derived IWV, OWS and CLW compare well with SSM/I and TMI finished products. Comparison of MSMR derived CLW with that derived from TMI and SSM/I is relatively in less agreement. This is possibly due to the use of $37 \mathrm{GHz}$ in SSM/I and TMI that is highly sensitive to CLW, while $37 \mathrm{GHz}$ channels are not available on MSMR. Monthly comparison of MSMR geophysical products with those from TMI is all carried out for climatological purpose. The monthly comparisons were much better compared to instantaneous comparisons. In this paper, details of the data analysis and comparison results are presented. The usefulness of the MSMR vis-à-vis other sensors is also discussed.

\section{Introduction}

Integrated Cloud Liquid Water (CLW), Integrated Water Vapour (IWV), Ocean Wind Speed (OWS), and Sea Surface Temperature (SST) are integral components of the ocean observation system. Their spatial and temporal distribution is required for both weather and climatic studies. The Multifrequency Scanning Microwave Radiometer (MSMR) onboard the Indian satellite IRS-P4 (Oceansat-1) has been providing measurements of these geophysical parameters (GPDs) over global oceans since June 1999.

MSMR channel combination was earlier available in SMMR on Seasat/Nimbus-7 in 1978-87. Despite calibration problems, Nimbus provided IWV, OWS and SST for a variety of useful applications. Subsequent to Nimbus was the DMSP
(Defense Meteorological Satellite Program) series of satellites, which carried the Special Sensor Microwave Imager (SSM/I) that provided CLW, IWV and OWS over global oceans since 1987. More recently, in 1998 the Tropical Rainfall Measuring Mission (TRMM) satellite was launched with a microwave radiometer (TMI) that provided global measurements of CLW, IWV, OWS and SST. Data from SSM/I and TMI have been very effectively used for rain rate measurements over land and oceans. An extensive comparison of GPDs from $\mathrm{SSM} / \mathrm{I}$ and TMI has been carried out with in situ and other satellites (Hollinger 1990, Alishouse et al 1990a and b; Goodberlet et al 1990; Varma et al 1998; Varma 1999).

For the effective use of the parameters, comparison of MSMR derived GPDs with in situ, model observations, and with similar products from other

Keywords. MSMR; TMI; SSM/I; geophysical products. 
Table 1. Salient features of retrieval algorithms.

\begin{tabular}{|c|c|c|}
\hline Features & MSMR algorithm & Wentz algorithm \\
\hline 1. Type & $\begin{array}{l}\text { Statistical technique using Radiative } \\
\text { Transfer Simulations (Gohil et al 2000) }\end{array}$ & $\begin{array}{l}\text { Minimization approach } \\
\text { between measured and } \\
\text { simulated brightness } \\
\text { temperatures (Wentz, } \\
\text { 1997). }\end{array}$ \\
\hline \multicolumn{3}{|l|}{ 2. Channels for- } \\
\hline IWV & $18 \mathrm{~V}, 18 \mathrm{H}, 21 \mathrm{~V}, 21 \mathrm{H}$ & V22, V37, H37 \\
\hline WS & $\begin{array}{l}6 \mathrm{~V}, 6 \mathrm{H}, 10 \mathrm{~V}, 10 \mathrm{H}, 18 \mathrm{~V}, 18 \mathrm{H}, 21 \mathrm{~V}, 21 \mathrm{H} \\
10 \mathrm{~V}, 10 \mathrm{H}, 18 \mathrm{~V}, 18 \mathrm{H}, 21 \mathrm{~V}, 21 \mathrm{H}\end{array}$ & V22, V37, H37 \\
\hline CLW & $18 \mathrm{~V}, 18 \mathrm{H}, 21 \mathrm{~V}, 21 \mathrm{H}$ & V22, V37, H37 \\
\hline SST & $6 \mathrm{~V}, 6 \mathrm{H}, 10 \mathrm{~V}, 10 \mathrm{H}, 18 \mathrm{~V}, 18 \mathrm{H}, 21 \mathrm{~V}, 21 \mathrm{H}$ & \\
\hline $\begin{array}{l}\text { 3. Other inputs in } \\
\text { retrieval algorithms }\end{array}$ & Climate SST and incidence angle & $\begin{array}{l}\text { Average SST and } \\
\text { incidence angle }\end{array}$ \\
\hline
\end{tabular}

satellites is essential. Ali (2000) has presented a comprehensive comparison of all GPDs (except CLW) with in situ and analysed fields, and found reasonably good agreement. Varma et al (1999) have compared scan mode MSMR derived CLW, IWV and OWS with similar products from SSM/I over the Indian Ocean region. The present study is aimed at inter-comparison of MSMR derived gridded products (except SST) with similar products from SSM/I and TMI over the global oceans.

The difference in MSMR GPDs with respect to SSM/I and TMI are due to the difference in their frequencies at which measurements are made, noise figures and algorithm. The basic features of retrieval algorithm for SSM/I and TMI, and MSMR are shown in table 1 , which shows the difference in the basic approach as well as the channels used.

\section{Instruments and data}

\subsection{IRS-P4 MSMR data}

MSMR on board IRS-P4 (Oceansat-I) provides measurement of brightness temperatures (Tbs) at $6.6,10,18$ and $21 \mathrm{GHz}$ frequencies in both horizontal and vertical polarisations. IRS-P4 is in a sun synchronous orbit with ascent at equator at $2340 \mathrm{hr}$ and descent at $1140 \mathrm{hr}$ local time. The four operational products available from MSMR are Cloud Liquid Water (CLW), Integrated Water Vapour (IWV), Ocean Surface Wind Speed (OWS) and Sea Surface Temperature (SST). MSMR products are generated in three resolution grids of 150 , 75 and $50 \mathrm{kms}$, respectively. Derivation of CLW and IWV use only high frequency channels, and they are available in all three grids. OWS is available in two grids of 150 and $75 \mathrm{~km}$, with the use of all 8 channels in $150 \mathrm{~km}$ grid, and use of 6 channels in $75 \mathrm{~km}$ grid (without $6 \mathrm{GHz}$ ). Derivation of SST
Table 2. Theoretical retrieval accuracy of MSMR GPDs.

\begin{tabular}{lccc}
\hline \multicolumn{1}{c}{ Parameter } & Tropic & Midlat & Polar \\
\hline SST (K) (grid 1) & 1.52 & 1.92 & 1.90 \\
OWS $\left(\mathrm{ms}^{-1}\right)$ (grid 1) & 1.63 & 1.59 & 1.51 \\
OWS $\left(\mathrm{ms}^{-1}\right)$ (grid 2) & 2.10 & 2.00 & 1.91 \\
IWV $\left(\mathrm{g} \mathrm{cm}^{-2}\right)$ ' (grids 1,2, 3) & 0.20 & 0.18 & 0.15 \\
CLW $\left(\mathrm{mg} \mathrm{cm}^{-2}\right)$ (grids 1, 2, 3) & 13.0 & 11.0 & 9.0 \\
\hline
\end{tabular}

uses all 8 channels and thus is available only in $150 \mathrm{~km}$ grid. Table 2 shows the theoretical accuracy of MSMR products.

MSMR geophysical data are available daywise $(24 \mathrm{hrs})$ in three grids as mentioned above, with data quality flag.

\section{$2.2 S S M / I$ and TMI data}

$\mathrm{SSM} / \mathrm{I}$ is a four frequency, seven channel radiometer. The SSM/I is operated at 19.35, 22.235, 37.0 and $85.5 \mathrm{GHz}$ frequencies. TMI frequencies are almost similar to SSM/I except for additional $10.7 \mathrm{GHz}$ frequency and a $21.3 \mathrm{GHz}$ frequency instead of $22.235 \mathrm{GHz}$ for SSM/I. TMI and SSM/I operate in dual polarizations, $V$ and $H$, except $22.235 \mathrm{GHz}$ that operates only in $V$ polarization. Three satellites which carry onboard SSM/I, namely F11, F13 and F14, are presently operational in sun-synchronous orbit with equator ascending time at 1925, 1754 and 2046 LST, respectively. On the other hand, TMI onboard TRMM (Tropical Rainfall Measuring Mission) satellite is in a low altitude (218 miles), low inclination, and non-sun-synchronous orbit.

The SSM/I -F13 and -F14 global swath mode data are provided by Global Hydrology Resource Centre (GHRC) of NOAA/USA. The data are available with footprint sampling resolution of $25 \mathrm{~km}$ for 19,22 and $37 \mathrm{GHz}$ channels (called low 

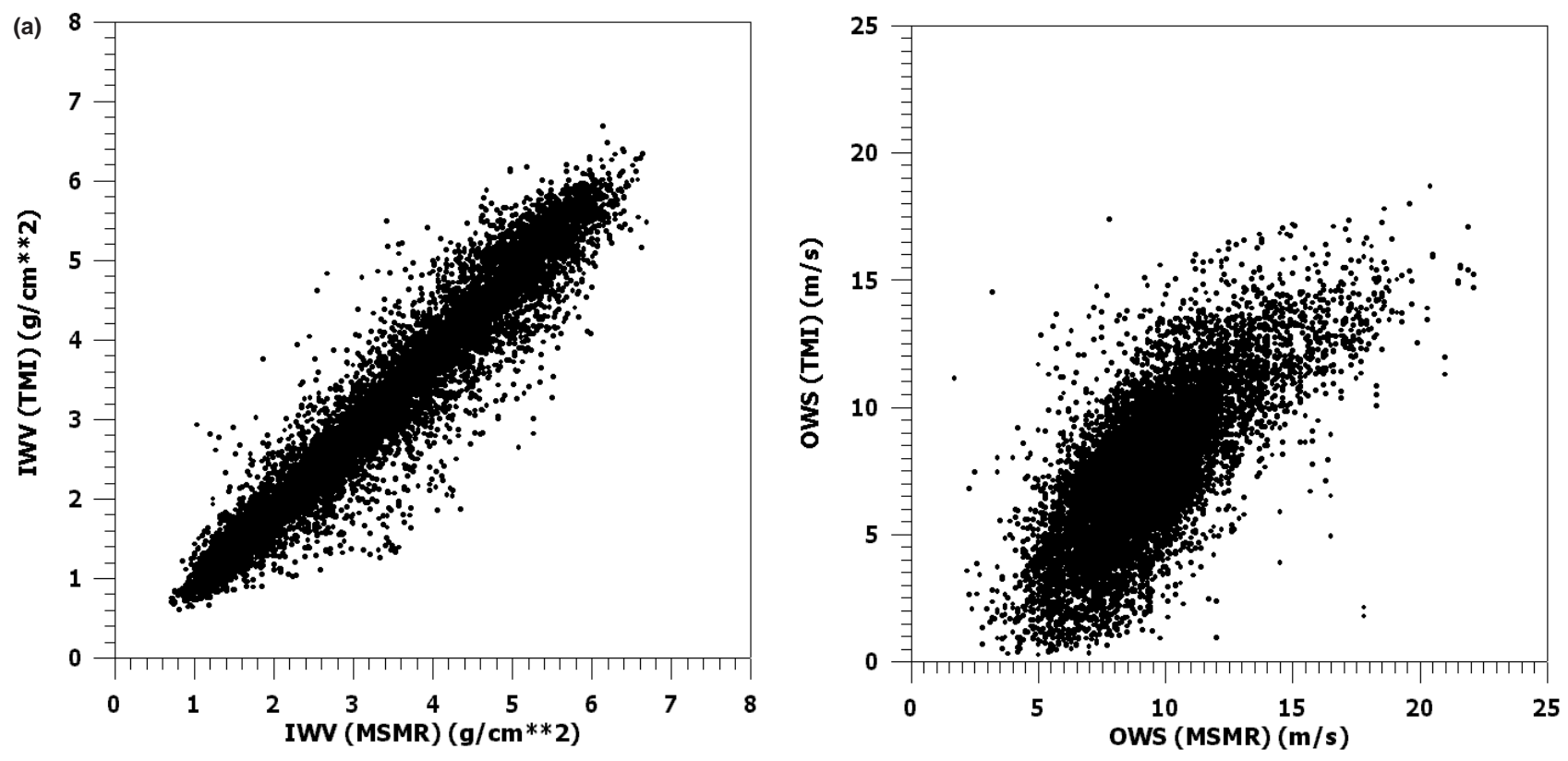

(b)

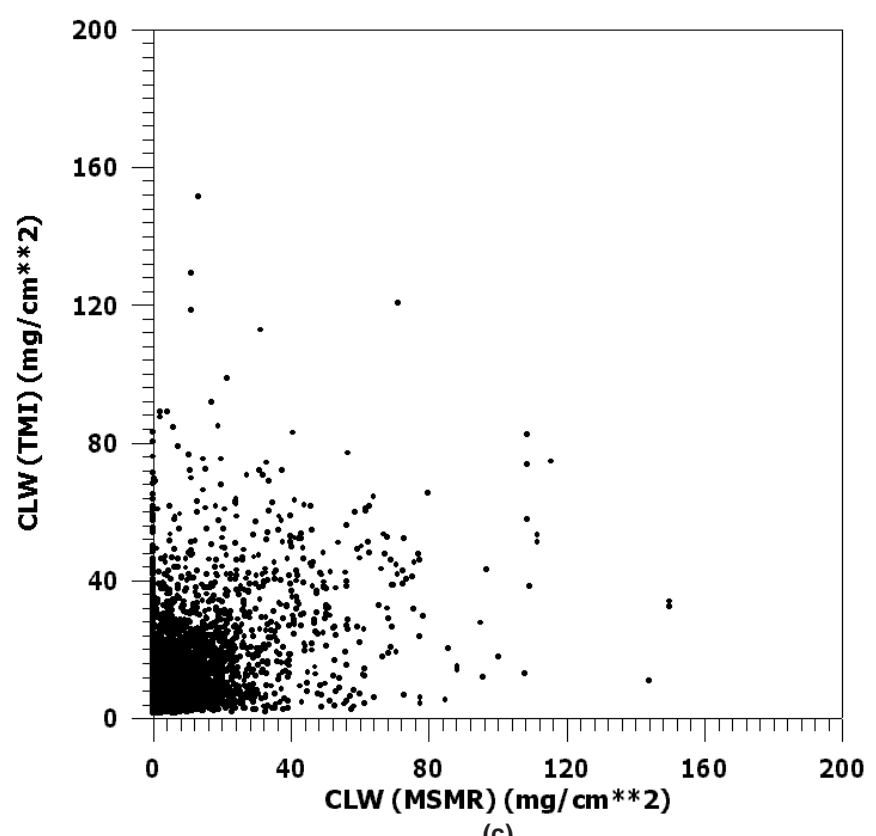

(c)

Figure 1. (a) Comparison of colocated and near simultaneous $(<1 \mathrm{hr}$.) global measurements of Integrated Water Vapour (IWV) from MSMR and TMI for $150 \mathrm{~km}$ grid. (b) Same as figure 1(a) but for Ocean Surface Wind Speed (OWS). (c) Same as figure 1(a) but for Cloud Liquid Water (CLW).

frequency channels) and $12.5 \mathrm{~km}$ for $85 \mathrm{GHz}$ channels (called high frequency channels) over a swath of $1400 \mathrm{~km}$. The data comprise brightness temperature of all seven channels and three derived geophysical parameters over oceans, viz., CLW, IWV and OWS in addition to the quality flags. A careful examination of OWS values in SSM/I data stream has revealed that OWS values are computed only when CLW is below $13.5 \mathrm{mg} \mathrm{cm} \mathrm{cm}^{-2}$.

The algorithms for TMI finished products are developed by Wentz, and the Wentz products are available from Global Hydrology Resource Centre
(GHRC), NASA, USA. In addition to CLW, IWV and OWS, TMI finished product also provided measurements of SST and rain rate. The accuracy of TMI products is not directly available but it is expected that they will have the accuracy of the same order (or even better) as that of SSM/I products. Careful examination of OWS values in TMI data stream indicate that OWS values are provided only when CLW is less than $\sim 33 \mathrm{mg} \mathrm{cm}^{-2}$.

Alishouse et al (1990b) also noted that SSM/I brightness temperatures are highly correlated with non-precipitating CLW over ocean. Accuracy of 
Table 3(a). Comparison of integrated water vapour: TMI vs. MSMR.

\begin{tabular}{ccccccccc}
\hline \multirow{2}{*}{ Grid } & Time & $\begin{array}{c}\text { No. of } \\
\text { pts. }\end{array}$ & Slope & Interc. & $\mathrm{R}$ & Bias & $\begin{array}{c}\text { S.D. of } \\
\text { diff. }\end{array}$ & $\begin{array}{c}\text { rms } \\
\text { diff. }\end{array}$ \\
\hline \multirow{3}{*}{$50 \mathrm{~km}$} & $<1 \mathrm{hr}$ & 27543 & 0.94 & -0.03 & 0.96 & -0.23 & 0.40 & 0.46 \\
& $<2 \mathrm{hr}$ & 44692 & 0.94 & -0.03 & 0.96 & -0.22 & 0.40 & 0.46 \\
& $<3 \mathrm{hr}$ & 60859 & 0.94 & -0.02 & 0.96 & -0.20 & 0.40 & 0.45 \\
\hline \multirow{2}{*}{$75 \mathrm{~km}$} & $<1 \mathrm{hr}$ & 26626 & 0.95 & -0.03 & 0.96 & -0.22 & 0.40 & 0.46 \\
& $<2 \mathrm{hr}$ & 43238 & 0.94 & -0.03 & 0.96 & -0.22 & 0.40 & 0.46 \\
& $<3 \mathrm{hr}$ & 58898 & 0.95 & -0.02 & 0.96 & -0.20 & 0.41 & 0.46 \\
\hline \multirow{2}{*}{$150 \mathrm{~km}$} & $<1 \mathrm{hr}$ & 10884 & 0.96 & -0.07 & 0.96 & -0.21 & 0.37 & 0.43 \\
& $<2 \mathrm{hr}$ & 17673 & 0.96 & -0.06 & 0.96 & -0.21 & 0.38 & 0.43 \\
& $<3 \mathrm{hr}$ & 23953 & 0.96 & -0.05 & 0.96 & -0.19 & 0.38 & 0.53 \\
\hline
\end{tabular}

Table 3(b). Comparison of integrated water vapour: SSM/I F14 vs. MSMR.

\begin{tabular}{rcccccccc}
\hline \multirow{2}{*}{ Grid } & Time & $\begin{array}{c}\text { No. of } \\
\text { pts. }\end{array}$ & Slope & Interc. & R & Bias & $\begin{array}{c}\text { S.D. of } \\
\text { diff. }\end{array}$ & $\begin{array}{c}\text { rms } \\
\text { diff. }\end{array}$ \\
\hline $50 \mathrm{~km}$ & $<2 \mathrm{hr}$ & 15245 & 0.99 & -0.23 & 0.95 & -0.26 & 0.49 & 0.55 \\
& $<3 \mathrm{hr}$ & 97411 & 0.97 & -0.17 & 0.95 & -0.23 & 0.47 & 0.52 \\
\hline $75 \mathrm{~km}$ & $<2 \mathrm{hr}$ & 13807 & 0.99 & -0.23 & 0.95 & -0.26 & 0.50 & 0.56 \\
& $<3 \mathrm{hr}$ & 97750 & 0.98 & -0.16 & 0.95 & -0.23 & 0.48 & 0.53 \\
\hline $150 \mathrm{~km}$ & $<2 \mathrm{hr}$ & 5065 & 1.01 & -0.27 & 0.95 & -0.26 & 0.48 & 0.54 \\
& $<3 \mathrm{hr}$ & 37618 & 0.99 & -0.18 & 0.95 & -0.22 & 0.45 & 0.51 \\
\hline
\end{tabular}

Table 4(a). Comparison of ocean wind speed (m/s): TMI vs. MSMR.

\begin{tabular}{ccccccccc}
\hline \multirow{2}{*}{ Grid } & Time & $\begin{array}{c}\text { No. of } \\
\text { pts. }\end{array}$ & Slope & Interc. & R & Bias & $\begin{array}{c}\text { S.D. of } \\
\text { diff. }\end{array}$ & $\begin{array}{c}\text { rms } \\
\text { diff. }\end{array}$ \\
\hline \multirow{3}{*}{$75 \mathrm{~km}$} & $<1 \mathrm{hr}$ & 24953 & 0.71 & 0.87 & 0.66 & -1.81 & 2.31 & 2.93 \\
& $<2 \mathrm{hr}$ & 40321 & 0.72 & 0.77 & 0.67 & -1.85 & 2.29 & 2.95 \\
& $<3 \mathrm{hr}$ & 54246 & 0.72 & 0.76 & 0.68 & -1.87 & 2.31 & 2.97 \\
\hline \multirow{3}{*}{$150 \mathrm{~km}$} & $<1 \mathrm{hr}$ & 10254 & 0.84 & -0.31 & 0.73 & -1.78 & 2.01 & 2.68 \\
& $<2 \mathrm{hr}$ & 16570 & 0.85 & -0.42 & 0.73 & -1.82 & 1.99 & 2.70 \\
& $<3 \mathrm{hr}$ & 22196 & 0.85 & -0.41 & 0.74 & -1.84 & 2.00 & 2.72 \\
\hline
\end{tabular}

Table 4(b). Comparison of ocean wind speed (m/s): SSM/I F14 vs. MSMR.

\begin{tabular}{ccccccccc}
\hline \multirow{2}{*}{ Grid } & Time & $\begin{array}{c}\text { No. of } \\
\text { pts. }\end{array}$ & Slope & Interc. & R & Bias & $\begin{array}{c}\text { S.D. of } \\
\text { diff. }\end{array}$ & $\begin{array}{c}\text { rms } \\
\text { diff. }\end{array}$ \\
\hline \multirow{2}{*}{$75 \mathrm{~km}$} & $<2 \mathrm{hr}$ & 9131 & 0.78 & 1.10 & 0.67 & -1.01 & 2.84 & 3.01 \\
& $<3 \mathrm{hr}$ & 66354 & 0.79 & 0.63 & 0.72 & -1.41 & 2.51 & 2.88 \\
\hline \multirow{2}{*}{$150 \mathrm{~km}$} & $<2 \mathrm{hr}$ & 3342 & 0.91 & -0.25 & 0.75 & -1.07 & 2.40 & 2.63 \\
& $<3 \mathrm{hr}$ & 25658 & 0.88 & -0.46 & 0.77 & -1.57 & 2.18 & 2.69 \\
\hline
\end{tabular}


Table 5(a). Comparison of cloud liquid water $\left(\mathrm{mg} / \mathrm{cm}^{2}\right)$ : TMI vs. MSMR.

\begin{tabular}{ccccccccc}
\hline \multirow{2}{*}{ Grid } & Time & $\begin{array}{c}\text { No. of } \\
\text { pts. }\end{array}$ & Slope & Interc. & R & Bias & $\begin{array}{c}\text { S.D. of } \\
\text { diff. }\end{array}$ & $\begin{array}{c}\text { rms } \\
\text { diff. }\end{array}$ \\
\hline \multirow{3}{*}{$50 \mathrm{~km}$} & $<1 \mathrm{hr}$ & 25923 & 0.42 & 7.97 & 0.52 & 4.42 & 12.91 & 13.64 \\
& $<2 \mathrm{hr}$ & 42240 & 0.39 & 8.14 & 0.50 & 4.40 & 13.18 & 13.90 \\
& $<3 \mathrm{hr}$ & 57530 & 0.38 & 8.32 & 0.49 & 4.40 & 13.59 & 14.29 \\
\hline \multirow{2}{*}{$75 \mathrm{~km}$} & $<1 \mathrm{hr}$ & 25077 & 0.36 & 8.33 & 0.48 & 4.57 & 13.82 & 14.56 \\
& $<2 \mathrm{hr}$ & 40894 & 0.34 & 8.45 & 0.46 & 4.54 & 13.99 & 14.71 \\
& $<3 \mathrm{hr}$ & 55716 & 0.34 & 8.62 & 0.45 & 4.54 & 14.32 & 15.03 \\
\hline \multirow{3}{*}{$150 \mathrm{~km}$} & $<1 \mathrm{hr}$ & 10219 & 0.44 & 7.95 & 0.44 & 5.39 & 10.60 & 11.89 \\
& $<2 \mathrm{hr}$ & 16670 & 0.42 & 8.00 & 0.44 & 5.32 & 10.65 & 11.91 \\
& $<3 \mathrm{hr}$ & 22616 & 0.41 & 8.19 & 0.42 & 5.39 & 10.92 & 12.18 \\
\hline
\end{tabular}

Table 5(b). Comparison of cloud liquid water $\left(\mathrm{mg} / \mathrm{cm}^{2}\right)$ : SSMI F14 vs. MSMR.

\begin{tabular}{ccccccccc}
\hline \multirow{2}{*}{ Grid } & Time & $\begin{array}{c}\text { No. of } \\
\text { pts. }\end{array}$ & Slope & Interc. & R & Bias & $\begin{array}{c}\text { S.D. of } \\
\text { diff. }\end{array}$ & $\begin{array}{c}\text { rms } \\
\text { diff. }\end{array}$ \\
\hline \multirow{2}{*}{$50 \mathrm{~km}$} & $<2 \mathrm{hr}$ & 14980 & 0.47 & 8.65 & 0.40 & 4.22 & 19.90 & 20.35 \\
& $<3 \mathrm{hr}$ & 87916 & 0.44 & 8.80 & 0.37 & 4.51 & 18.55 & 19.09 \\
\hline \multirow{2}{*}{$75 \mathrm{~km}$} & $<2 \mathrm{hr}$ & 11882 & 0.51 & 10.13 & 0.42 & 6.04 & 20.37 & 21.25 \\
& $<3 \mathrm{hr}$ & 76868 & 0.47 & 10.14 & 0.38 & 6.04 & 19.08 & 20.02 \\
\hline \multirow{2}{*}{$150 \mathrm{~km}$} & $<2 \mathrm{hr}$ & 4408 & 0.55 & 9.74 & 0.38 & 6.64 & 17.78 & 18.98 \\
& $<3 \mathrm{hr}$ & 29620 & 0.51 & 10.04 & 0.33 & 6.90 & 17.55 & 18.85 \\
\hline
\end{tabular}

CLW from SSM/I is $10 \mathrm{mg} \mathrm{cm}^{-2}$ over oceans (Hollinger 1990; Alishouse et al 1990b). They further found that $37 \mathrm{GHz}$ is alone a good predicator of CLW with a correlation coefficient of 0.87 between surface and satellite measurements. The accuracy of the IWV over oceans measured from $\mathrm{SSM} / \mathrm{I}$ is found as $0.2 \mathrm{~g} \mathrm{~cm}^{-2}$ over a range of 0 to $8 \mathrm{~g} \mathrm{~cm}^{-2}$ (Alishouse 1990a; Hollinger 1990). The comparison of SSM/I OWS with in situ data has revealed an accuracy of $2 \mathrm{~ms}^{-1}$ over the range of 3 to $25 \mathrm{~ms}^{-1}$ (Goodberlet et al 1990). A detailed comparison of SSM/I winds with Geosat-Altimeter and TOPEX-altimeter has been earlier carried out (Varma et al 1998; Varma 1999). In all the cases a good correlation is found between two measurements of OWS.

\section{Data Analysis and Results}

\subsection{Comparison of concurrent observations of $I W V, C L W$ and $O W S$ from MSMR with TMI and $S S M / I$}

For comparison of IWV, CLW and OWS, we have used global MSMR data on different grids (50, 75 and $150 \mathrm{kms}$ ) of 7 days of July, 1999. Data are colocated with near concurrent SSM/I and TMI finished products. As the SSM/I and TMI are available on higher resolution, before analysis, data are averaged on three different MSMR grids.
MSMR data over all three grids is colocated with $\mathrm{SSM} / \mathrm{I}$ and TMI data separately, in $1^{\circ} \times 1^{\circ}$ spatial and 1, 2 and 3 hours of temporal bins. If in this space-time bin, more than one data point is found colocated in any bin, average value is computed. Figure 1 ( $a, b$, and $c$ ) shows, comparison of IWV, OWS and CLW from MSMR and TMI within 1 hour (i.e., colocated in 1 hour temporal bin) for $150 \mathrm{~km}$ grid. Table 3(a) and (b) shows comparison statistics of IWV derived from MSMR with that derived from TMI and SSM/I-F14, respectively. A good comparison of MSMR derived IWV is observed with TMI and SSM/I derived IWV in all the three grids and temporal differences. Table 4(a) and (b) shows comparison statistics of OWS derived from MSMR with that derived from TMI and SSM/I-F14, respectively. OWS from MSMR is available only in $75 \mathrm{~km}$ and $150 \mathrm{~km}$ grids. In $75 \mathrm{~km}$ grid OWS estimation is carried out without the use of $6 \mathrm{GHz}$ channel, whereas in $150 \mathrm{~km}$ grid all 8 channels are used for wind estimation. A reasonably good comparison of MSMR derived OWS is observed with TMI and SSM/I derived OWS in both the grids and with different temporal differences. It may be noted here that MSMR OWS is derived with the use of all 8 channels (i.e., in $150 \mathrm{~km}$ grid) is better correlated with TMI and MSMR OWS than that measured with only 6 channels (i.e., without the use of $6 \mathrm{GHz}$ channels) in $75 \mathrm{~km}$ grid. Tables 5(a) and (b) show comparison statistics of CLW derived from MSMR with 

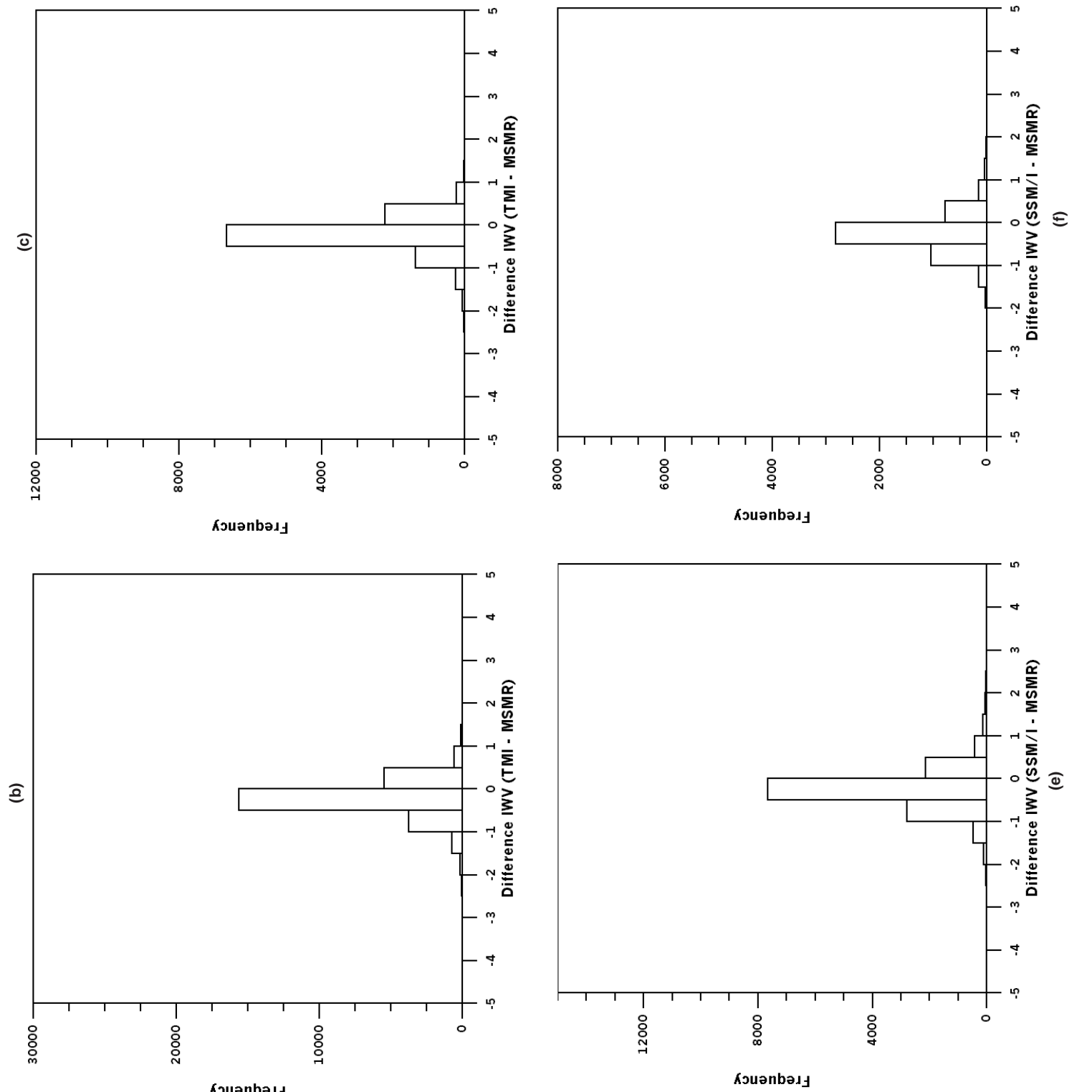

$\sum \frac{\dot{m}}{\square}$
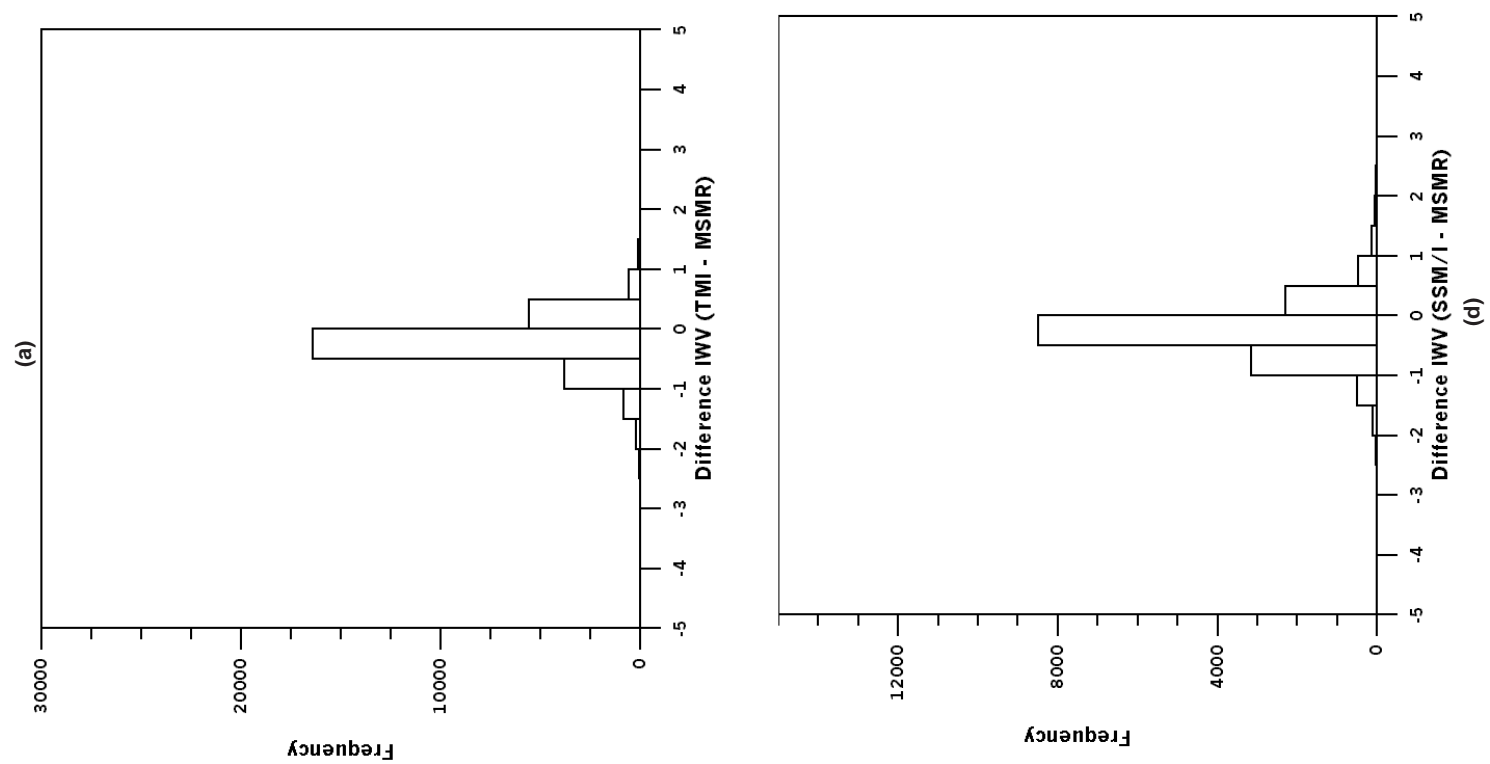

蓱

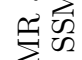

足

의

记

过

范

루

कृष

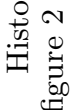

نิ

(ซ)

ํี

$\stackrel{3}{3}$

运 
Table 6. Comparison of IWV, OWS and CLW from TMI and SSM/I-F14.

\begin{tabular}{|c|c|c|c|c|c|c|c|c|}
\hline Para. & Time & $\begin{array}{l}\text { No. of } \\
\text { pts. }\end{array}$ & Slope & Interc. & $\mathrm{R}$ & Bias & $\begin{array}{l}\text { S.D. of } \\
\text { diff. }\end{array}$ & $\begin{array}{l}\text { rms } \\
\text { diff. }\end{array}$ \\
\hline IWV & $<1 \mathrm{hr}$ & 5153 & 1.04 & -0.26 & 0.99 & -0.09 & 0.18 & 0.20 \\
\hline OWS & $<1 \mathrm{hr}$ & 4279 & 0.89 & 0.61 & 0.92 & -0.21 & 1.11 & 1.13 \\
\hline CLW & $<1 \mathrm{hr}$ & 4769 & 1.20 & 0.25 & 0.84 & 2.44 & 10.60 & 10.87 \\
\hline
\end{tabular}
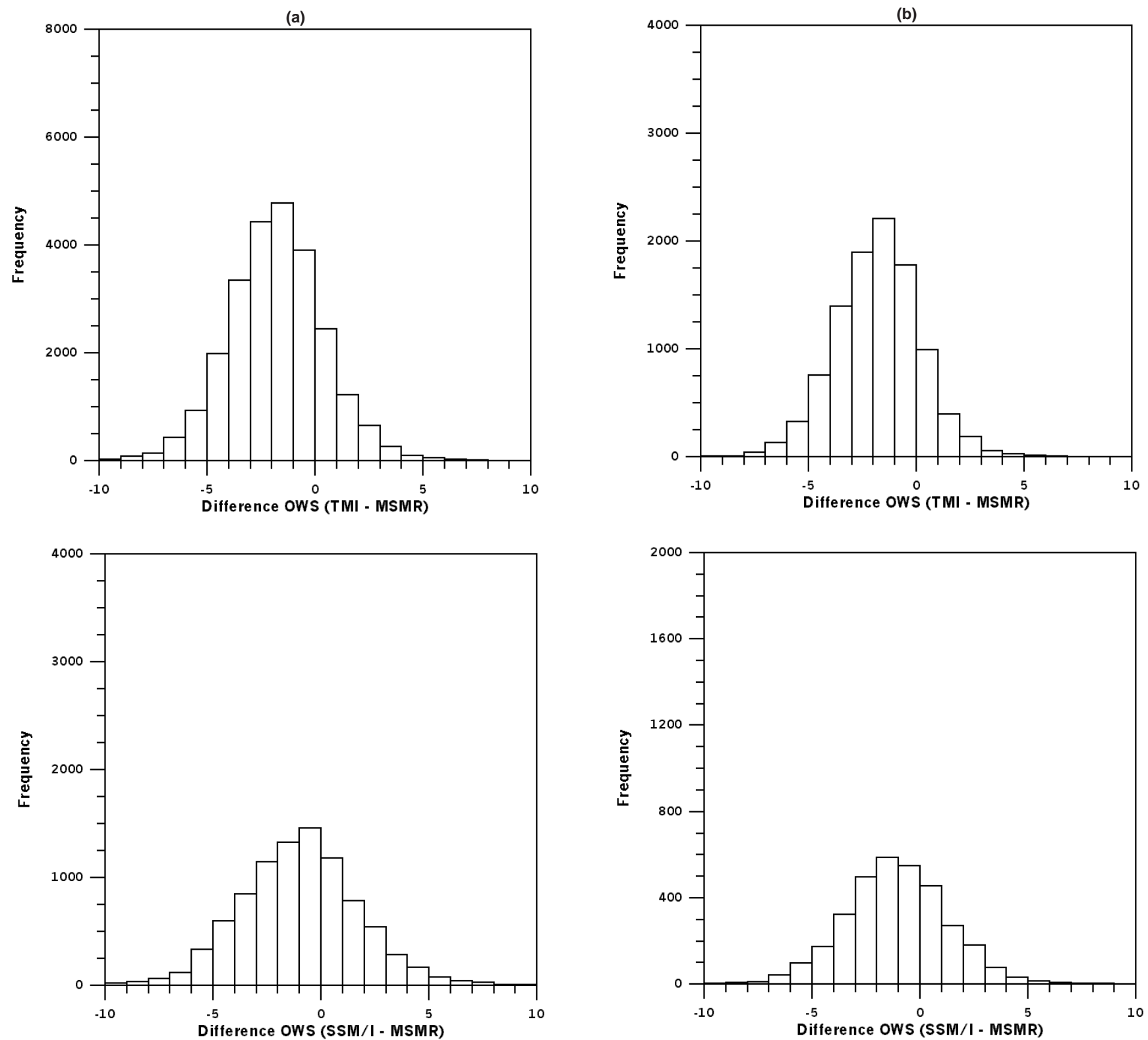

(c)

(d)

Figure 3. (a-b). Same as figure 2(b-c) but for OWS. (c-d). Same as figure 2(e-f) but for OWS.

that derived from TMI and SSM/I-F14, respectively. The results are not very encouraging. This may be partly because of high spatial and temporal variability of the CLW, and partly because of the absence of $37 \mathrm{GHz}$ channels in MSMR which is highly (about 87\%) correlated with the CLW (Alishouse 1990b).
In order to establish the consistency of the present results of MSMR comparison of IWV, OWS and CLW with other sensors, a further study of comparison of these parameters from TMI and $\mathrm{SSM} / \mathrm{I}$ is also carried out and briefly presented in table 6 . It is found that these parameters from TMI and SSM/I match very well with a high value 

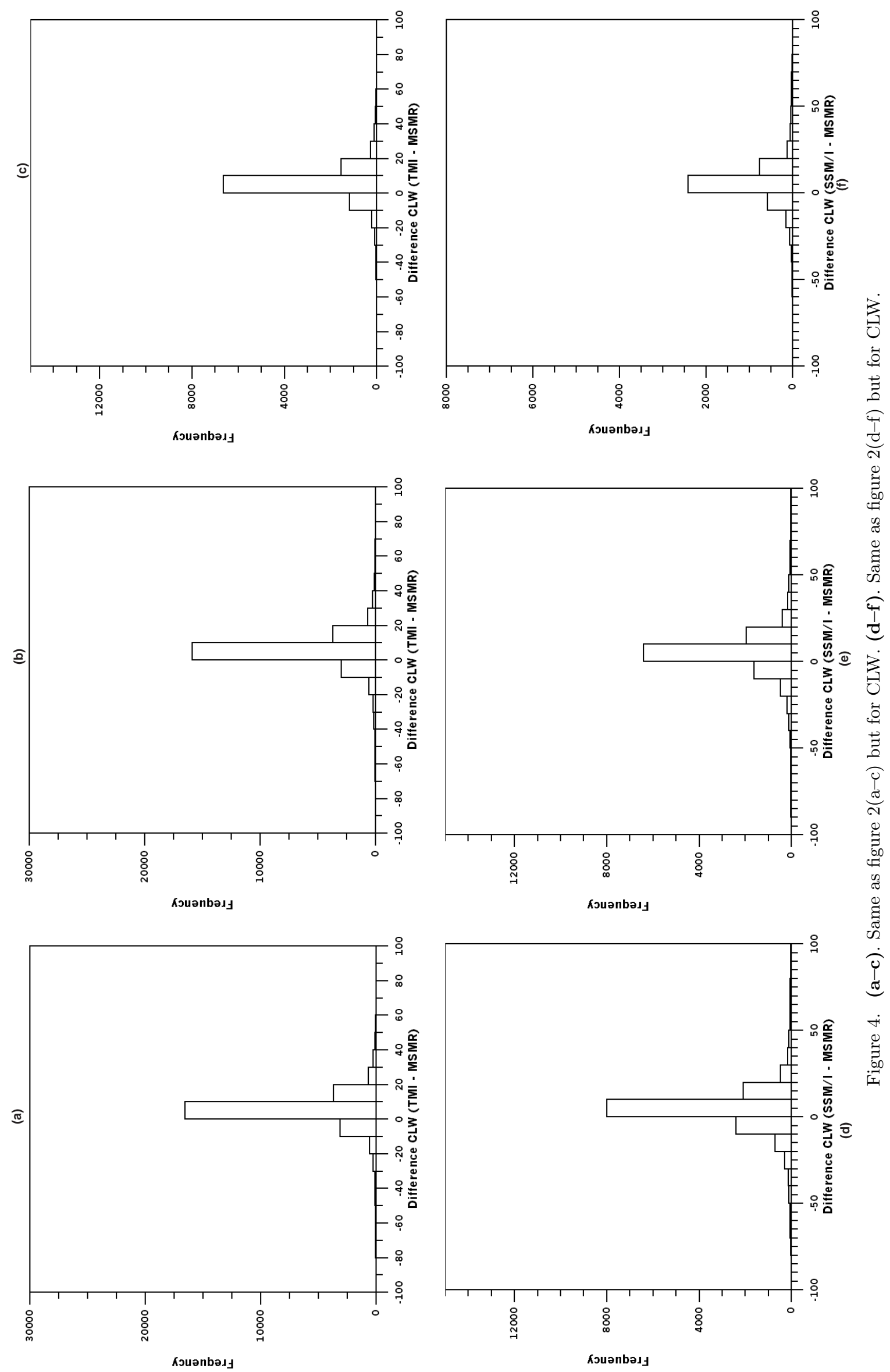
(a)

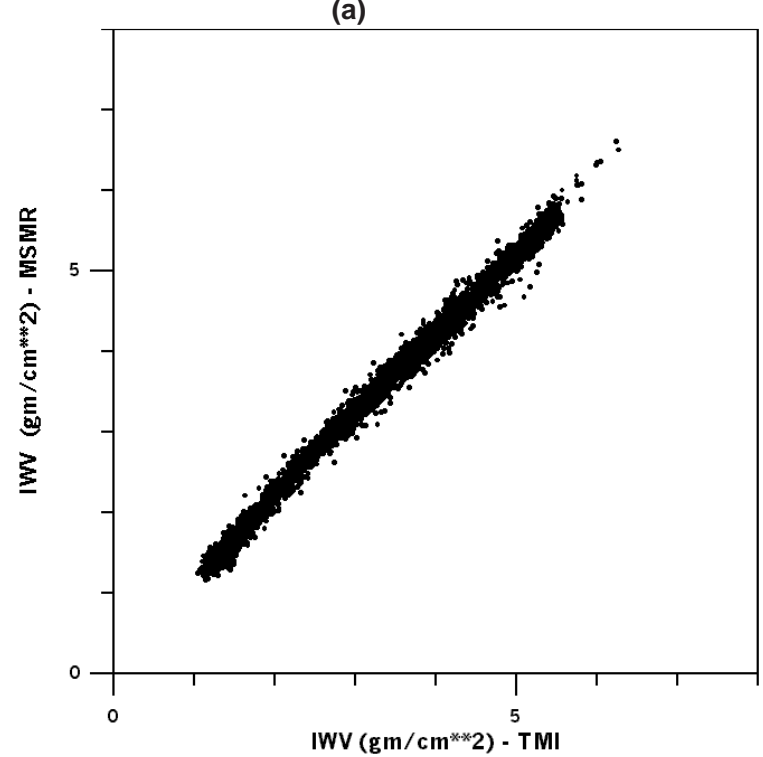

(b)

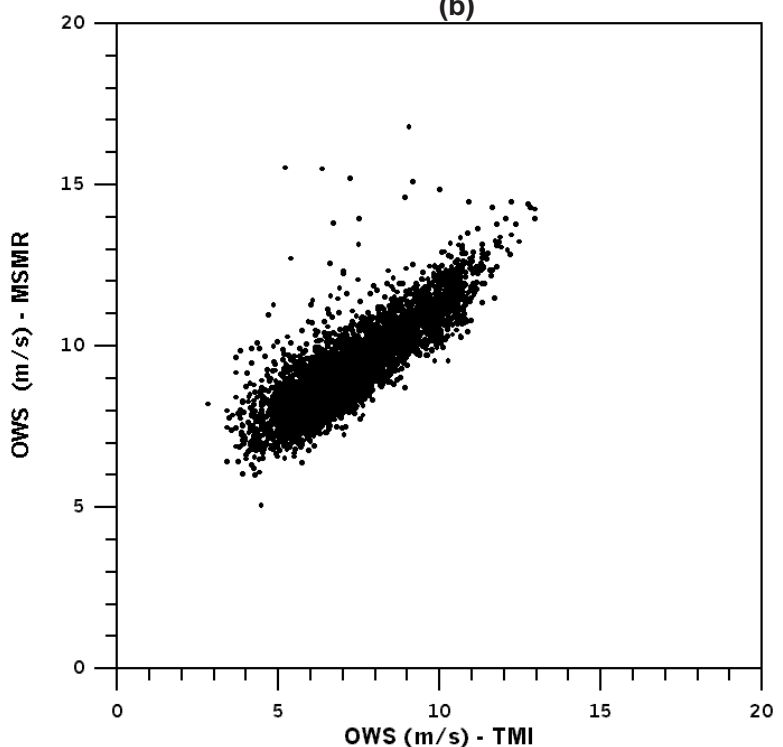

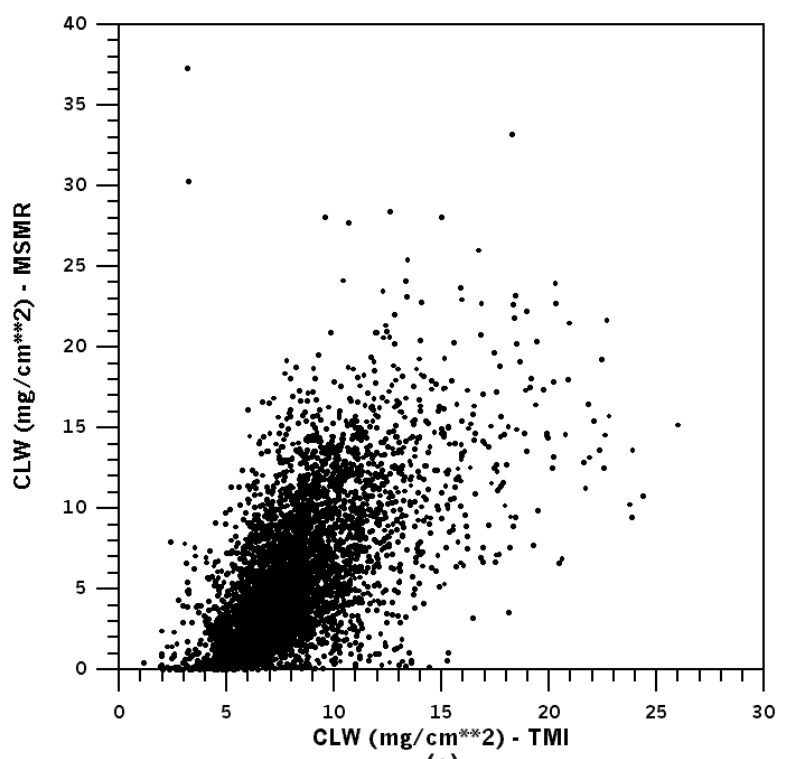

(c)

Figure 5. (a-c). Comparison of monthly averaged and grided $\left(2^{\circ} \times 2^{\circ}\right)$ IWV, OWS, and CLW from MSMR and TMI.

Table 7. Comparison of monthly averaged fields from MSMR and TMI.

\begin{tabular}{lccrcccc}
\hline Para. & $\begin{array}{c}\text { No. of } \\
\text { pts. }\end{array}$ & Slope & Interc. & R & Bias & S.D. of diff. & rms diff. \\
\hline IWV & 4524 & 0.99 & -0.18 & 1.00 & -0.20 & 0.10 & 0.23 \\
OWS & 4524 & 1.05 & -2.52 & 0.84 & -2.07 & 0.89 & 2.25 \\
CLW & 4524 & 0.40 & 5.90 & 0.62 & 2.33 & 3.55 & 4.25 \\
\hline
\end{tabular}

of correlation coefficient, less bias and root mean square (rms) difference. This is since both the TMI and SSM/I have more similarity compared to MSMR.

We have also plotted the difference of IWV, OWS and CLW from TMI and MSMR and from $\mathrm{SSM} / \mathrm{I}$ and MSMR, in all the grids (figures 2, 3 and 4). It is found that except CLW, IWV and OWS are slightly over estimated by MSMR as compared to TMI and SSM/I. CLW is generally underestimated by MSMR. For IWV about $80 \%$ of the points fall within $0.5 \mathrm{gm} \mathrm{cm}^{-2}$ of the difference and $96 \%$ falls within $1.0 \mathrm{gm} \mathrm{cm}^{-2}$ of the difference. Similarly, for OWS within the differ- 
ence of $3 \mathrm{~m} / \mathrm{s}, 70 \%$ points fall without use of the $6 \mathrm{GHz}$ channel, and $73 \%$ with the use of the $6 \mathrm{GHz}$ channel. In the case of CLW, about $76 \%$ points fall within the difference of $10 \mathrm{mg} \mathrm{cm}^{-2}$ from TMI observations.

\subsection{Comparison of monthly fields from MSMR with TMI}

In order to establish the coherence of MSMR derived GPDs on monthly scale that may show its usefulness for climatological studies, we have averaged MSMR and TMI derived parameters on a monthly scale and plotted them in figure 5. MSMR and TMI fields are averaged for the month of August 1999 in a grid of $2^{\circ} \times 2^{\circ} \quad$ (latitude-longitude). As expected the monthly fields of MSMR are better compared with TMI. Other statistical details are given in table 7 .

\section{Conclusions and discussion}

MSMR derived IWV values have a very good agreement with TMI and SSM/I derived IWV values with high correlation, low bias and rms difference. Results do not vary significantly with grid size. On the other hand, MSMR derived OWS values in $150 \mathrm{~km}$ grid are in better agreement with TMI and $\mathrm{SSM} / \mathrm{I}$ derived values. This is partly because of the inclusion of $6 \mathrm{GHz}$ brightness temperatures in the retrieval algorithm and partly because of the reduction of noise in large sized grids. MSMR derived CLW is not in good agreement with TMI and $\mathrm{SSM} / \mathrm{I}$ derived values. This is possibly because of the absence of $37 \mathrm{GHz}$ channels and high variability of the CLW.

Statistics presented in figures reveal that MSMR, in general, over estimates OWS and IWV as compared to TMI and SSM/I. However a critical look at the figures, reveal that lower values of the OWS are under estimated by MSMR and high values are over estimated.

\section{Acknowledgement}

We are thankful to Global Hydrology Resource Centre, NASA for providing scan mode SSM/I and TMI data, and Remote Sensing Systems for providing grided TMI data. We are also thankful to Director, SAC, Deputy Director, RESA/SAC, and Group Director, MOG/SAC for their encouragement.

\section{References}

Ali M M 2000 Validation of Multifrequency Scanning Microwave Radiometer geophysical parameter data products; Proc. of Pacific Ocean Remote Sensing Conference - 2000, 5-8 December 2000, NIO, Goa, India, pp 182-191.

Alishouse J C, Synder S A, Vongsathorn J and Ferraro R R 1990a Determination of oceanic total water from the SSM/I; IEEE Trans. Geosci. and Remote Sens. 28, 811816

Alishouse J C, Synder J B, Westwater E R, Swift C L, Ruf C S, Synder S A, Vongsathorn J and Ferraro R R 1990b Determination of cloud liquid water content using the SSM/I; IEEE Trans. Geosci. and Remote Sens. 28 $817-822$

Gohil B S, Mathur A K and Varma A K 2000 Geophysical parameter retrieval over global oceans from IRSP4/MSMR; Proc. of Pacific Ocean Remote Sensing Conference - 2000, 5-8 December 2000, NIO, Goa, India, pp 207-211

Goodberlet M A, Swift C T and Wilkerson J C 1990 Ocean surface wind speed measurements of the Special Sensor Microwave/Imager (SSM/I); IEEE Trans. Geosci. and Remote Sens. 28 823-828

Hollinger J P 1990 Introduction IEEE; Trans. Geosci. and Remote Sens. 28 (5) 779-780

Varma A K, Gairola R M, Basu S, Singh K P and Pandey P C 1998 A comparative study of near concurrent DMSP-SSM/I and Geosat-altimeter measurements of ocean winds over the Indian oceanic region; Int. J. Remote Sens. 19 717-730

Varma A K 1999 Remote sensing studies on some aspects of ocean environment; PhD thesis, B.H.U., Varanasi, p.185

Varma A K, Gairola R M and Gohil B S 1999 Comparison of IRS-P4 MSMR and DMSP-SSM/I Geophysical Products, SAC/ISRO report No. ISRO/SAC/RESA/MOG/OSD/MSMR/TN/DEC-03, p 44.

Wentz F J 1997 A well calibrated ocean algorithm for Special Sensor Microwave Imager; Journal of Geophysical Research, 102 (C4) pp 8703-8718 